\title{
O Lugar da Experiência na Fenomenologia de E. Husserl: de Prolegômenos a Ideias I
}

\author{
Carlos Diógenes C. Tourinho
}

\begin{abstract}
RESUMO: O artigo aborda o lugar da experiência nas origens da fenomenologia, em Prolegômenos à Lógica Pura (1900). Mostra-nos que Husserl assume uma posiçẫo específica quanto ao papel da experiência no debate sobre a relação entre a lógica e a psicologia. $\mathrm{O}$ artigo trata ainda dos reflexos da posição husserliana em Ideias I (1913), a propósito da temática da constituiçấo dos objetos intencionais. Husserl indica o papel decisivo assumido pelos dados sensíveis, na medida em que servem de "suporte" para a intencionalidade. Destaca-se a concepção segundo a qual a doaçâo de sentido que se dá através dos atos intencionais da consciência não deriva dos dados sensíveis, porém, não começa sem eles.
\end{abstract}

PALAVRAS-CHAVE: Fenomenologia. Edmund Husserl. Experiência. Dados Sensíveis. Vivência Intencional.

\section{INTRODUÇÁO}

O presente artigo tem como objetivo destacar, primeiramente, a importância do lugar reservado à experiência nas origens da fenomenologia, especificamente, no Quarto Capítulo de "Prolegômenos à Lógica Pura" (1900), primeiro volume das Investigaçóes Lógicas de Husserl. Pretendese mostrar que, perante a conhecida controvérsia entre os psicologistas e os lógicos antipsicologistas, assumir uma posição quanto ao papel da experiência na discussão sobre a relação entre a lógica e a psicologia era algo de fundamental importância para que se pudesse propor, naquele contexto, uma terceira linha de investigação, a partir da qual nasceria a filosofia fenomenológica. Afinal, se os psicologistas tomam, ao reeditarem um empirismo no último quarto do século XIX, a experiência como fonte do conhecimento, assumindo, com base na doutrina naturalista, o pressuposto segundo o qual conceber o mundo significa concebê-lo estritamente como uma realidade de fatos naturais (tomando os processos psicológicos como ponto de partida para a fundamentação da lógica), os argumentos apresentados pelos lógicos antipsicologistas - apesar de não incorrerem nos equívocos psicologistas - não

\footnotetext{
${ }^{1}$ Doutor em Filosofia pela PUC-Rio. Professor do Departamento de Filosofia e do Programa de PósGraduação em Filosofia da Universidade Federal Fluminense - UFF. Email: cdctourinho@yahoo.com.br
} 
foram, nos termos de Husserl, adequadamente trabalhados, permanecendo os mesmos "obscurecidos por diversas incorreçóes" 2 . Nesse sentido, na referida fundamentação, os adeptos da lógica "formal" apoiam-se unicamente em estruturas meramente formais, prescindindo completamente da experiência. $\mathrm{O}$ artigo apontará que, em linguagem kantiana, Husserl assume, ao final do Quarto Capítulo de "Prolegômenos", uma posição específica, reservando um lugar especial à experiência (tomando-a não como "fonte", mas como começo de todo o conhecimento; afinal, as leis lógicas não são inferências da experiência psicológica, embora só por meio dela se possam conhecer) ${ }^{3}$. Husserl não incorre, assim, nem em um empirismo nos moldes psicologistas, nem tampouco em um formalismo logicista. Sua opção será, conforme veremos, pela ideia de uma "vivência originária" que é, por definição, intencional, mas que não pode prescindir de "dados sensíveis" sobre os quais os atos intencionais da consciência irão atuar no próprio vivido. Destaca-se a posição husserliana quanto ao lugar reservado à experiência, em 1913, em Ideias I, a propósito da temática da constituição dos objetos intencionais. Ao tomar a intencionalidade como "objetividade imamente", situando-a em uma região transcendental, Husserl afirma-nos que, na trama da constituição intencional, os dados sensíveis (materiais ou hiléticos) assumem um papel decisivo, na medida em que, no fluxo do vivido em geral, servem de "suporte" para a intenção que, por sua vez, anima o vivido de significaçôes. Reaparece a concepção segundo a qual a doação de sentido que se dá através dos atos intencionais da consciência não deriva dos dados sensíveis, porém, não começa sem eles. Acompanhemos, então, em "Prolegômenos" (1900), bem como em Ideias I (1913), a posição de Husserl quanto ao lugar reservado à experiência.

\section{A crítica ao psicologismo e o lugar da experiênCia em "Prolegômenos"}

Pode-se dizer que, em "Prolegômenos", o momento crucial repousa sobre as críticas de Husserl ao psicologismo - cujo equívoco maior consistiria na insistência dos psicólogos do último quarto do século XIX em buscar uma fundamentação para as leis da lógica nos processos psíquicos, em tomar as leis do pensamento em termos de leis psicofísicas, propondo uma espécie de "física do pensamento" ${ }^{4}$. Tal insistência psicologista culminaria, de acordo

\footnotetext{
${ }^{2}$ Cf. HUSSERL, Logische Untersuchungen. Erster Band. Prolegomena zur reinen Logik, $\$ 20$, p. 59.

${ }^{3}$ Cf. HUSSERL, Logische Untersuchungen. Erster Band. Prolegomena zur reinen Logik, \$24, p. 81-82.

${ }^{4}$ Lipps afirma-nos que: "A Lógica é física do pensar ou ela não é nada" ("Die Logik ist Physik des Denkens oder sie ist überhaupt nichts”). Cf. Idem, $\$ 19$, p. 55.
} 
com Husserl, em um ceticismo e em um relativismo nocivos à pretensão de fundamentação da filosofia e que deveria, portanto, ser evitado a todo custo. Entre os psicologistas do final do século XIX citados por Husserl, tais como Lipps, Stuart Mill, dentre outros, prevalece a convicção segundo a qual os fundamentos da lógica se encontram na própria psicologia, de maneira que a lógica consistiria apenas em uma parte ou ramo da ciência psicológica. Nos termos de Lipps: "A lógica é uma disciplina psicológica, tão certo quanto o conhecer só ocorre na psique, e o pensar, que nele se completa, é um acontecer psíquico"s. Em tal concepção psicologista, caberia à psicologia fornecer o fundamento teórico para a construção de uma técnica lógica e, de acordo com tal concepção, jamais se poderia afastar da lógica o seu conteúdo psicológico. Para os adeptos do psicologismo, tal conteúdo psicológico indissociável já estaria presente nos conceitos constitutivos das leis lógicas, tais como os conceitos de "verdade" e "falsidade", "afirmação" e "negação", "universalidade" e "particularidade", "premissa” e "conseqüência”, e assim por diante ${ }^{6}$.Enquanto "ciência de fatos" (e, portanto, enquanto "ciência experimental"), a psicologia - ao modo de consideração das ciências positivas - adota a indução como método de investigação. Procede habitualmente por observação sistematizada de fatos particulares, procurando descrever a regularidade do que é observado para inferir, então, o que os cientistas positivistas denominam "leis gerais" Husserl esforça-se em mostrar que, enquanto regras meramente empíricas (isto é, "aproximativas"), inferidas através da indução exercida pela ciência psicológica, tais "leis gerais" carecem de exatidão absoluta, pois a validade dessas leis depende de "circunstâncias" e, desse modo, não são "leis"... no sentido autêntico da palavra. Para Husserl, todas as leis alcançadas por indução consistem, na medida em que carecem de validade absoluta, em leis de probabilidade ${ }^{7}$.

Nesse sentido, essas mesmas leis psicológicas não poderiam ser confundidas com as leis da lógica (os princípios lógicos, as leis da silogística etc.), cuja validade é a priori, cuja fundamentação e justificação se dão não por meio da indução, por meio de suposiçóes probabilísticas, mas por evidências apodíticas apreendidas por intelecção.

\footnotetext{
5 "Die Logik ist eine psychologische Disziplin, so gewiß das Erkennen nur in der Psyche vorkommt und das Denken, das sich in ihm vollendet, ein psychisches Geschehen ist". Cf. HUSSERL, Logische Untersuchungen. Erster Band. Prolegomena zur reinen Logik, $\$ 18$, p. 52.

${ }^{6}$ Cf. Idem, $\$ 18$, p. 52.

${ }^{7}$ Cf. Idem, $\$ 22$, p. 65.
} 
Daí o próprio Husserl ressaltar, no $\$ 21$, que “[...] a probabilidade não pode se impor contra a verdade, ou a conjectura contra a intelecção" ${ }^{8}$. O erro dos psicologistas em tomar as puras leis do pensamento em termos de leis causais da natureza, confinando-as à esfera do probabilismo, parece resultar, de acordo com Husserl, das confusóes produzidas pelo próprio modo de consideração naturalista acerca do problema em questão, mais precisamente, por não levar em conta a distinção crucial entre as leis lógicas (entendidas como "conteúdos do juízo") e os próprios juízos, no sentido de "atos de julgar", acontecimentos reais dotados de causas e efeitos. Confunde-se, por conseguinte, em tal modo de consideração, a lei do pensar com o ato de julgar (em outros termos, "o ideal com o real").

Tal confusão leva-nos a conceber a lei como reguladora do processo do pensamento, acrescentando-se, com isso, uma segunda confusão produzida pelo naturalismo entre a "lei lógica" que se refere ao conteúdo do conhecimento e a "lei psicológica" que, em conformidade com a anterior, regularia o processo cognoscitivo. Husserl procura alertar para os perigos dessa segunda confusão, afirmando-nos, no famoso "exemplo da máquina de calcular" (ao final do $\$ 22$ dos "Prolegômenos"), que há de se considerar a heterogeneidade entre as "leis gerais da aritmética" e as "leis mecânicas" que explicam o funcionamento da máquina. Ninguém apelaria, ao tentar explicar tal funcionamento, para as leis da aritmética em detrimento das leis mecânicas determinantes do funcionamento da máquina9 . O erro maior dos psicologistas do último quarto do século XIX consistiria, por conseguinte, em ignorar as diferenças fundamentais e essenciais entre "lei ideal" e "lei real", entre "regulação normativa" e "regulação causal", entre "necessidade lógica" e "necessidade real", entre "fundamento lógico" e "fundamento real". As leis causais segundo as quais o pensamento se desenvolve de modo a poder se justificar pelas normas ideais da lógica, e estas mesmas normas seriam, portanto, para Husserl, coisas inteiramente distintas.

Husserl deixa-nos claro que, ao identificar as leis do conteúdo do ato com as leis que regulam o processo psicológico, os psicologistas acabam por fazer com que a verdade que constitui o conteúdo do ato dependa diretamente do processo psíquico, isto é, da constituição da natureza humana, o que inevitavelmente nos levaria a afirmar que tal verdade não existiria, se não existisse essa constituição. Mais uma vez, Husserl chama-nos a atenção

\footnotetext{
8"Wahrscheinlichkeit kann nicht gegen Wahrheit, Vermutung nicht gegen Einsicht streiten”. Cf. Ibidem. , $\$ 21$, p. 64.

${ }^{9}$ Cf. HUSSERL, Logische Untersuchungen. Erster Band. Prolegomena zur reinen Logik, $\$ 22$, p. 68.
} 
para o que entende ser fundamental: não podemos confundir o juízo como "conteúdo de juízo" (isto é, como unidade ideal) com o ato de julgar, concreto e real. A psicologia refere-se aos juízos como "assentimentos" (ou "atos de consciência"), ao passo que a lógica considera o juízo como "unidade ideal de significação".

Husserl lembra-nos, no $₫ 19$, que os partidários do que poderíamos chamar de um "antipsicologismo logicista" (tais como, Jäsche, Herbart, dentre outros) não deixam de fundamentar uma separação rigorosa entre a lógica e a psicologia. Nesse sentido, contestam toda tentativa de fundamentação da lógica na psicologia, afirmando-nos que a psicologia toma o pensar como ele $e ́$ (enquanto ato psíquico), ao passo que a lógica o concebe como deve ser. Se a disciplina psicológica - na investigação positiva do processo psicofísico - se ocupa com "leis da natureza", a lógica ocupa-se com leis normativas do pensar. Enquanto "ciência de fatos" (e, portanto, enquanto ciência experimental), a psicologia esclarece-nos, através da investigação dos processos psicofísicos, como o pensar acontece, conduzindo-nos, como em toda ciência positiva, a generalizaçóes empíricas que, como tais, são meramente contingentes. $\mathrm{Na}$ lógica, porém, trata-se não de regras contingentes (de caráter "circunstancial" ou "episódico"), mas, necessárias - não de como pensamos, mas de como devemos pensar. Os lógicos lembram-nos ainda que a psicologia investiga as conexôes reais entre os processos de consciência, ao passo que à lógica interessa examinar não essas conexôes naturais, mas "conexôes ideais" entre proposiçóes.

Em geral, contra essa argumentação, os psicologistas apoiam-se na objeção segundo a qual náo poderíamos falar em leis lógicas se nunca tivéssemos tido representaçóes ou juízos atualmente vividos e deles abstraído os correspondentes conceitos lógicos fundamentais. Em suma, os psicologistas perguntam-nos: como os lógicos poderiam buscar as conexôes ideais, sem levar em consideração as conexôes naturais presentes nos processos psicofísicos? Afinal, objetam os psicologistas, ainda que se admita tal distinção entre o real e o ideal (entre o ato de pensar e o conteúdo lógico do pensamento), todo raciocínio lógico é indissociável do ato psicológico de pensar.Husserl responde, no $\$ 23$, a essa objeção psicologista, afirmando-nos que não se nega que as leis lógicas se manifestem através de atos psicológicos, mas “[...] os pressupostos psicológicos ou componentes da afirmação duma lei não se podem confundir com os elementos lógicos do seu conteúdo" ${ }^{10}$. Tal redução psicologista das leis

10 "[...] und daßpsychologische Voraussetzungen oder Ingredienzien der Behauptung eines Gesetzes nicht mit logischen Momenten seines Inhaltes vermengt werden dürfen". Cf. HUSSERL, Logische Untersuchungen. 
lógicas às leis psicológicas teria, conforme frisamos, levado Lipps a considerar a lógica uma "física do pensamento" ". Tida como uma disciplina da psicologia, a lógica seria, na concepção de Lipps, uma "ciência indutiva". Todo esforço de Husserl consiste em mostrar, ao denunciar os equívocos cometidos pelos psicologistas, que dos fatos náo podemos haurir leis de caráter absoluto, de modo que, se o saber humano estivesse, em última instância, fundado na psicologia, todo ele ficaria inconsistente (teríamos assim profundamente abalado o valor de todo o conhecimento) e, por conseguinte, estaria aberto o caminho para um ceticismo radical que "[...] é, por definição, evidentemente contraditório" 12 . Portanto, para Husserl, não poderemos confundir o modo concreto como se manifestam as leis lógicas com as mesmas leis em si. Husserl recupera, então, ao final do Capítulo Quarto de "Prolegômenos", no $\$ 24$ (Continuação), a lição - anunciada por Kant na Introdução da Crítica da Razão Pura: "Todo o conhecimento 'começa com a experiência', mas não 'deriva', só por isso, da experiência"13. Em outros termos, as leis lógicas não são inferências da experiência psicológica, embora só por meio dela se possam conhecer. Tal insistência psicologista em não reconhecer tais distinçóes entre o conteúdo do ato de julgar e o ato propriamente dito, entre as leis lógicas e as leis psicológicas, culminaria, conforme Husserl, em um ceticismo e em um relativismo nocivos à pretensão de fundamentação da filosofia como "ciência rigorosa" e que deveria, portanto, ser evitado a todo custo. Por outro lado, apesar de reconhecer o mérito dos lógicos antipsicologistas de não incorrer nos equívocos psicologistas, de não confundir o ideal e o real (o ato de julgar com o conteúdo lógico do juízo), Husserl não deixa de ressaltar, ao final do Capítulo Terceiro, no $\$ 20$, que, da parte dos lógicos antipsicologistas, os pensamentos decisivos apresentados contra o psicologismo náo foram adequadamente trabalhados, permanecendo os mesmos "[...] obscurecidos por diversas incorreçóes" ${ }^{14}$.

Erster Band. Prolegomena zur reinen Logik, $\$ 23$, p. 71.

${ }^{11}$ Cf. Idem, $\$ 19$, p. 55.

${ }^{12}$ Cf. Idem, $\$ 32$, p. 112.

13 “Alle Erkenntnis fängt mit der Erfahrung an', aber sie 'entspringt' darum nicht schon aus der Erfahrung”. Cf. HUSSERL, Logische Untersuchungen. Erster Band. Prolegomena zur reinen Logik, $\$ 24$, p. 81-82. Já na edição B da Crítica da Razão Pura (Kritik der reinen Vernunft), Kant afirmara-nos: "Se, porém, todo o conhecimento se inicia com a experiência, isso não prova que todo ele derive da experiência" (Wenn aber gleich alle unsere Erkenntniss $m$ it der Erfahrung anhebt, so entspringt sie darum doch nicht eben alle aus der Erfahrung). Cf. Kant, I. Kritik der reinen Vernunft, Einleitung. Leipzig: Felix Meiner, ([1787] 1919), p. 47.

${ }^{14}$ Cf. HUSSERL, Logische Untersuchungen. Erster Band. Prolegomena zur reinen Logik, $\$ 20$, p. 59. 
Se os psicologistas se equivocam, na discussão sobre a relação entre a lógica e a psicologia, pela insistência em fundamentar a lógica em fatos de consciência, confundindo as leis do pensamento com as leis causais da natureza, os lógicos antipsicologistas confinam-nos, na referida discussão, apesar de não incorrerem nos equívocos psicologistas, à esfera de estruturas meramente formais, afastando-nos da questão acerca do estatuto da relaçáo entre o ideal e o real. Vê-se, então, Husserl diante de duas exigências, já nas origens da fenomenologia: contra o psicologismo, seria preciso sustentar uma dualidade, a distinção entre o ideal e o real (entre o ato psicológico de pensar e o conteúdo lógico do pensamento), sem se isentar, contudo, de pensar o estatuto da relação entre os atos de pensamento e seus conteúdos ideais questáo afastada pelos adeptos da lógica formal, por não aceitarem nenhum tipo de relação entre o "empírico" e o "formal". A ideia de um "vivido" (Erlebniss) originário - que é, por definição, intencional, mas que não pode prescindir de um substrato sensível sobre o qual irâo atuar, no próprio vivido, os atos intencionais da consciência - é a aposta de Husserl para atender a essa dupla exigência. É o que examinaremos mais atentamente, a partir de agora.

\section{O VIVIDO INTENCIONAL E SUA RELAÇÃO COM OS DADOS SENSÍVEIS}

Pode-se dizer que o conceito de "intencionalidade" assume, em Husserl, um papel crucial no projeto da filosofia fenomenológica. Como herança do pensamento de Brentano, Husserl retém a ideia básica segundo a qual a intencionalidade é a peculiaridade da experiência de ser consciente de alguma coisa. Husserl conservará, ao longo do seu percurso filosófico, o sentido primordial dessa intencionalidade em relação às vivências cognoscitivas. Daí ele próprio afirmar, na "Quarta Lição" de A Ideia da Fenomenologia: "As vivências cognoscitivas possuem - isto pertence à sua essência - uma intentio, visam alguma coisa, se reportam de tal ou tal maneira a um objeto"15. Partindo dessa mesma suposição, Husserl definirá, no $\$ 84$ de Ideias I, a intencionalidade como "[...] a peculiaridade em virtude da qual as vivências são vivências de alguma coisa" ${ }^{\prime \prime}$. E, ainda, no $\$ 14$ de Meditaçóes Cartesianas, o mesmo pensamento nos é apresentado novamente, porém, de um modo mais completo: "A palavra intencionalidade não significa outra coisa senão esta particularidade fundamental e geral da consciência de ser consciente de alguma

${ }^{15}$ Cf. HUSSERL, E. Die Idee der Phänomenologie - Fünf Vorlesungen, p. 55.

${ }^{16}$ Cf. HUSSERL, E. Ideen zu einer reinen Phänomenologie und phänomenologischen Philosophie. Erstes Buch: Allgemeine Einführung in die reine Phänomenologie, $\$ 84$, p. 168. 
coisa, de portar, em sua qualidade de cogito, seu cogitatum nela mesma"17. Husserl chegará mesmo a sublinhar, no $\$ 84$ de Ideias $I$, que o conceito de intencionalidade é um conceito inicial e fundamental, absolutamente indispensável no início da fenomenologia.O primeiro contato de Husserl com o referido conceito - cuja origem remonta à tradição aristotélico-tomista - se dá por intermédio dos cursos proferidos por Brentano, entre 1884 e 1886, na Universidade de Viena. É na obra de Tomás de Aquino que Brentano busca fundamentos para reeditar a questáo da intencionalidade, no último quarto do século XIX. Para Tomás de Aquino, existir na natureza é distinto de existir no pensamento. As coisas existiriam fora da alma sob o modo de "coisa natural" (esse naturale) e no intelecto sob o modo de "coisa intencional" (esse intentionale). Apoiando-se nesse segundo modo de existência, no qual as coisas existem no intelecto enquanto "coisas pensadas", Brentano propóe uma teoria imanentista da intencionalidade, ao conceber a relaçáo intencional entre ato e objeto a partir de uma reedição da concepção aristotélico-tomista de "inexistência intencional" (intentionale Inexistenz) de um objeto ${ }^{18}$. Trata-se aí de uma "in-existência" não no sentido de "não existir", mas no sentido de "existir em": o objeto intencionado "in-existe" como tal no próprio pensamento. A in-existência intencional de um objeto presente em todo ato mental deve ser, portanto, entendida em termos de uma "objetividade imanente" (immanenten Gegenständlichkeit). O campo fenomenal se abre revelando, em sua imanência, a referência intencional aos objetos. No que se refere à originalidade de Husserl quanto ao referido conceito, nota-se, sobretudo, a partir de 1907, nas "Cinco Liçôes”, que as investigaçóes em torno da intencionalidade não habitariam mais o domínio do que é meramente empírico. Amplia-se a esfera de investigação acerca da intencionalidade, cabendo agora examinar os elementos que, no ato intencional da consciência pura, são responsáveis pela constituição das diferentes modalidades do "aparecer" enquanto tal. O problema da intencionalidade aparece, a partir desse momento, intimamente associado à ideia da "constituição dos objetos". Conforme ficaria mais claro em Ideias I

\footnotetext{
${ }^{17}$ Cf. HUSSERL, E. Cartesianische Meditationen und Pariser Vorträge, $\$ 14$, p. 72.

${ }^{18}$ Brentano confirma-nos, em 1874, o resgate dessa terminologia em uma passagem bem conhecida do $\$ 5$ do Capítulo 1 do Livro II de sua Psicologia do Ponto de Vista Empírico (Psychologie vom empirischen Standpunkt), ao ressaltar que "[t]odo fenômeno psíquico está caracterizado pelo que os escolásticos da Idade Média chamaram a inexistência intencional (ou mental) de um objeto, e que nós chamaríamos, embora com expressóes não inteiramente inequívocas, a referência a um conteúdo, a direção para um objeto (pelo qual nâo se deve entender aqui uma realidade), ou a objetividade imanente. Todo fenômeno psíquico contém em si algo como seu objeto, embora nem todos do mesmo modo. Na representação há algo representado; no juízo há algo admitido ou rechaçado; no amor, amado; no ódio, odiado; no apetite, apetecido, etc.”. Cf. BRENTANO, F. Psychologie vom empirischen Standpunkt, p. 124-125.
} 
(1913), diferentemente de Brentano, para quem a relação intencional ainda se mantinha em uma dimensáo meramente psicológica, Husserl procuraria situar, através da redução fenomenológica, a intencionalidade em uma região transcendental, independente de - e anterior a — toda descrição psicológica, recuperando, assim, de um modo original, a ideia de "objetividade imanente". Tratar-se-á, pois, com a intencionalidade, de uma propriedade essencial da consciência transcendental cuja presença "vivifica" a vivência (Erlebniss), tornando-a designativa de um objeto. No $\$ 36$ de Ideias I, Husserl afirma-nos que é da essência de todo cogito atual "ser consciência de algo", de tal modo que todos os vividos que possuem tal propriedade são chamados de "vividos intencionais" (ou "atos intencionais", se optarmos por um termo adotado à época das Investigaçôes Lógicas), uma vez que tais vividos são "consciência de algo". Pode-se dizer que são "intencionalmente referidos" a esse algo ${ }^{19}$. Porém, para Husserl, nem todas as vivências (ou atos) são intencionais. Trata-se de uma constatação para a qual o próprio Husserl já nos chamava a atenção, desde as Investigaçóes Lógicas (1900/1901), enfatizando, no $\$ 10$ da V Investigação, que existem "atos não-intencionais". Husserl cita-nos como exemplo de atos nãointencionais as próprias sensaçóes, indicando-nos, no mencionado parágrafo: "Que nem todas as experiências sejam intencionais é provado pela [existência de] sensaçóes e complexos sensacionais" ${ }^{20}$. No $\ 11$ da mesma V Investigaçáo, procurando exemplificar atos do tipo "náo-intencional", faz ainda a seguinte colocação: "Não vejo impressôes de cores, mas coisas coloridas; não ouço impressôes de sons, mas a canção cantada, etc." ${ }^{21}$. Portanto, para Husserl, novamente, nos termos de Ideias I, por "vivência", devemos entender tudo aquilo que se pode encontrar no fluxo de vividos em geral:

[...] náo apenas por conseguinte os vividos intencionais, as cogitationes atuais e potenciais tomadas em sua plena concreção, mas todos os momentos reais (reellen) suscetíveis de serem descobertos neste fluxo e em suas partes concretas 22 .

${ }^{19}$ Cf. HUSSERL, E. Ideen zu einer reinen Phänomenologie und phänomenologischen Philosophie. Erstes Buch: Allgemeine Einführung in die reine Phänomenologie, p. 64.

20 "Daß nicht alle Erlebnisse intentionale sind, zeigen die Empfindungen und Empfindungskomplexionen". Cf. HUSSERL, E. Logische Untersuchungen. Zweiter Band. Erster Teil. Untersuchungen zur Phänomenologie und Theorie der Erkenntnis, $\$ 10$, p. 369.

21 "Ich sehe nicht Farbenempfindungen, sondern gefärbte Dinge, ich höre nicht Tonempfindungen, sondern das Lied der Sängerin usw”. Cf. Idem, $\$ 11$, p. 374.

${ }^{22}$ Cf. Husserl, E. Ideen zu einer reinen Phänomenologie und phänomenologischen Philosophie. Erstes Buch: Allgemeine Einführung in die reine Phänomenologie, $\$ 36, \mathrm{p} 65$. 
O conceito de "vivido" (Erlebniss) remete-nos, então, no $\$ 36$ de Ideias $I$, para o fluxo de vividos em geral, englobando tanto os vividos desse fluxo que possuem a propriedade de "ser consciência de algo", quanto os "momentos reais" que, por serem apenas dados, nada designam ainda e, por consequência, encontram-se desprovidos de tal propriedade intencional, tais como os dados de sensação (Empfindungsdaten), os dados de cor, de tato, de som e semelhantes. Husserl ilustra-nos, no mesmo $\$ 36$ de Ideias $I$, a presença desses momentos não-intencionais, bem como a relação entre os mesmos e a intencionalidade no fluxo de vividos, dando-nos como exemplo o vivido da percepção do papel branco. Nele, deparamo-nos com o dado de sensação "branco", dado esse que, de acordo com Husserl, pertence inseparavelmente à essência da referida percepção, enquanto seu componente real. "Como conteúdo exibidor do branco do papel que aparece, ele é suporte de uma intencionalidade, mas não é ele mesmo uma consciência de algo"23. $\mathrm{O}$ mesmo vale, na perspectiva de Husserl, para outros dados de vivido, como, por exemplo, os chamados "sentimentos sensíveis" (sinnlichen Gefühlen). Cabe lembrar que, já nas Investigaçóes Lógicas ( $\$ 11$ do Segundo Capítulo da V Investigação), Husserl chamava-nos a atenção para a ideia segundo a qual os dados sensíveis aparecem como suporte do ato intencional, afirmando-nos que tais dados edificam (bauen) o ato, possibilitam (ermöglichen) a intenção, ainda que eles próprios não sejam intentados ${ }^{24}$.

No parágrafo $\$ 85$ de Ideias $I$, Husserl retoma o tema em questão, destacando-nos que, no fluxo de vividos, além da "camada intencional" - que "anima" a vivência de significaçóes, tornando-a designativa de um objeto todo vivido possui um "substrato" sensível e, como vimos, "não-intencional". Segundo Husserl, tal substrato - na medida em que é suporte para uma intencionalidade - se torna uma peça importante para o entendimento da trama que envolve a formação intencional (ou as doaçóes de sentido de diferentes níveis) no vivido como um todo. A "camada intencional" age sobre os momentos sensíveis, "animando-os", dando-lhes sentido (sinngebende). Trata-se, para Husserl, de uma camada por meio da qual o próprio vivido intencional se realiza, "[...] a partir do elemento sensual que em si nada tem

\footnotetext{
23 "Als darstellender Inhalt für das erscheinende Weiß des Papieres ist es Träger einer Intentionalität, aber nicht selbst ein Bewußtsein von etwas”. Cf. Idem, $\$ 36$, p. 65.

${ }^{24}$ Cf. HUSSERL, E. Logische Untersuchungen. Zweiter Band. Erster Teil. Untersuchungen zur Phänomenologie und Theorie der Erkenntnis, $\$ 11$, p. 374 .
} 
de intencional' 25 . Vê-se que a cogitatio é decomposta em duas partes: os momentos sensíveis (não-intencionais) e a camada intencional. Apesar dessa dualidade, Husserl não deixa de enfatizar o laço que os une, uma vez que, no vivido como um todo, os dados sensíveis seriam como a "matéria" (que nada tem de intencional, mas que, todavia, serve de "substrato" para a formação intencional), ao passo que a camada intencional seria como a "forma" (cujo papel no vivido seria propriamente o de promover a doação de sentido). Ainda que essa doação de sentido não derive da matéria, não começa sem ela, pois é sobre a matéria que a camada intencional agirá, atribuindo-lhe significação. Em todo vivido em geral, essa dualidade e essa unidade observável da Ylh (bylé) sensual e da morfh (morphé) intencional representarão um papel importante. Nos termos de Husserl, no $\$ 85$ de Ideias I: "Dados sensíveis se dão como matéria para formaçóes intencionais ou doaçôes de sentido de diferentes níveis..." 26 . Tais "dados sensíveis" - substrato da intencionalidade recebem, em Husserl, o nome de "dados hiléticos" (ou materiais), enquanto o que introduz no vivido a especificidade da intencionalidade recebe o nome de "momento noético" (noetisches Moment) ou pura e simplesmente noese. Conforme Husserl, a noese constitui o que é específico do noûs no sentido mais amplo da palavra, remetendo-nos para as cogitationes e vividos intencionais em geral e, portanto, para uma de suas significaçôes mais eminentes: a "doação de sentido" 27 . Por fim, Husserl conclui o $\$ 85$ de Ideias $I$, afirmando-nos que o fluxo dos vividos ("o fluxo do ser fenomenológico") possui uma "camada material" e uma "camada noética". A consideração e análise fenomenológica cuja atençấo se concentra especificamente em torno dos dados hiléticos (ou materiais) poderá ser chamada de hilético-fenomenológica; ao passo que a consideração referente aos momentos noéticos poderá ser chamada de noético-fenomenológica. Husserl deixa-nos claro que, das duas modalidades de análise fenomenológica, a mais importante e incomparavelmente mais rica se encontra do lado noético ${ }^{28}$.

No $\$ 86$ de Ideias I, Husserl destaca-nos ainda mais a importância da análise noético-fenomenológica, ao nos chamar a atenção para a relevância assumida pelos chamados "problemas funcionais": problemas referentes

${ }^{25}$ Cf. HUSSERL, E. Ideen zu einer reinen Phänomenologie und phänomenologischen Philosophie. Erstes Buch: Allgemeine Einführung in die reine Phänomenologie, $\$ 85$, p. 172.

${ }^{26}$ Cf. Idem, $\$ 85$, p. $172-173$.

${ }^{27}$ Cf. Idem, $\$ 85$, p. 174.

${ }^{28}$ Cf. HUSSERL, E. Ideen zu einer reinen Phänomenologie und phänomenologischen Philosophie. Erstes Buch: Allgemeine Einführung in die reine Phänomenologie, $\$ 85$, p. 175. 
à "constituição das objetividades da consciência". Tais problemas dizem respeito ao modo como as noeses - animando o material e entrelaçando-se em conteúdos e sínteses unificadoras do diverso (man-nigfaltig-einheitlichen) - produzem consciência "de" alguma coisa ${ }^{29}$. Husserl esclarece-nos, então, que, quando nos referimos aos "problemas funcionais", o termo "função" assume um sentido bem singular, fundado na essência pura das noeses: na doação de sentido que "vivifica o vivido". Portanto, o referido termo assume um sentido diferente daquele que lhe é atribuído pela matemática. O ponto de vista funcional torna-se, assim, segundo Husserl, central para a fenomenologia, concentrando-se em torno do modo como unidades objetivas se "constituem para a consciência". Novamente, Husserl aponta para a primazia das consideraçôes e análises noético-fenomenológicas sobre a análise hilética: "Naturalmente, a hilética pura se subordina à fenomenologia da consciência transcendental" 30 . Apesar de tal primazia, Husserl alerta-nos para o fato de que a própria hilética - concebida com uma disciplina autônoma e, como tal, dotada de um valor em si própria - assume, do ponto de vista funcional, a sua importância, uma vez que proporciona "[...] uma trama possível no tecido intencional, uma matéria possível para formaçôes intencionais" 31 . Seja como for, na visão de Husserl, ela se encontra, não somente pela dificuldade, mas também pela hierarquia de problemas relativos à ideia de um conhecimento absoluto, bem abaixo da fenomenologia noética.

\section{ConsideraçóEs FINAIS}

Conforme vimos, já em 1900, em "Prolegômenos", primeiro volume das Investigaçôes Lógicas, perante a controvérsia entre os psicologistas e os lógicos antipsicologistas, Husserl se vê diante de uma dupla tarefa: por um lado, para impedir a disseminação dos equívocos psicologistas, era necessário apresentar argumentos contundentes que reiterassem o discernimento entre o real e o ideal (entre "leis naturais" e "leis do pensamento"), evitando, pois, as confusôes resultantes do projeto psicologista de fundamentação da lógica na psicologia. Porém, tal discernimento não isentaria Husserl de pensar o estatuto da relaçấo entre o conteúdo lógico do pensamento e o próprio ato

${ }^{29}$ Cf. HUSSERL, E. Ideen zu einer reinen Phänomenologie und phänomenologischen Philosophie. Erstes Buch: Allgemeine Einführung in die reine Phänomenologie, \$ 86, p. 176.

30 "Natürlich ordnet sich die reine Hyletik der Phänomenologie des transzendentalen Bewußtseins unter". Cf. Idem, $\$ 86$, p. 178 .

${ }^{31}$ Idem, $\$ 86$, p. 178. 
psicológico de pensar. Afinal, como ele próprio reconhece, é inegável que o primeiro somente se dê por intermédio do segundo ("Ninguém duvidará de que o conhecimento das leis lógicas como ato psíquico, pressupóe a experiência particular de que esse conhecimento tem os seus fundamentos na intuição concreta") $)^{32}$, o que não significa, contudo, que tenhamos que confundir os "pressupostos" psicológicos com os pressupostos, razóes ou premissas lógicas da lei. Eis uma segunda tarefa decisiva para Husserl: redimensionar o estatuto da relação entre o ato psicológico de pensar e o seu conteúdo ideal.

Em Do Empirismo à Fenomenologia - A crítica do psicologismo nas Investigaçóes Lógicas de Husserl ([1972] 2010), José Henrique Santos concordará, igualmente, com essa interpretação, quando escreve: "Chegamos assim ao ponto crucial da questáo: como se relaciona a idealidade do pensamento com sua produção real?" 33 A aceitação de tal dualidade entre as fronteiras do ideal e do real não nos isentaria, ao contrário do que pensam os adeptos da lógica formal, de pensar o estatuto da relação entre tais domínios. Eis, assim, uma "dupla tarefa" fundamental com a qual Husserl se depara em "Prolegômenos". Ainda nos termos de José Henrique Santos: "Antes de mais nada, é preciso elucidar a questão das relações e diferenças entre o real e o ideal, pois a soluçáo deste problema é preliminar à dos demais" ${ }^{34}$.

O leitor atento não deixará, contudo, de constatar que, ao final do Terceiro Capítulo de "Prolegômenos", ao afirmar que os argumentos decisivos apresentados pelos adeptos da lógica formal não foram "adequadamente trabalhados", encontrando-se inclusive "obscurecidos por diversas incorreçôes", Husserl talvez pudesse, nessa passagem do texto, ter elucidado um pouco mais para o leitor o que haveria de "inadequado" na argumentação dos adversários do psicologismo. Afinal, ao se ocuparem unicamente em distinguir as fronteiras da psicologia e da lógica, o que sem dúvida seria uma primeira tarefa necessária para evitar os problemas de fundamentos nos quais o psicologismo incorrera, por entenderem que tais fronteiras jamais se misturariam, tais autores (como Hamilton, Herbart, dentre outros, adeptos da lógica formal) acabariam por afastar completamente a pergunta a respeito da relação entre o real e o ideal. Tal afastamento da questão proporcionou, de certo modo, uma espécie de "contra-

32 "Niemand wird bezweifeln, daß die Erkenntnis der logischen Gesetze, als psychischer Akt, die Einzelerfahrung voraussetzt, daß sie ihre Grundlage hat in der konkreten Anschaunng". Cf. HUSSERL, Logische Untersuchungen. Erster Band. Prolegomena zur reinen Logik, $\$ 24$, p. 75.

${ }_{33}$ Cf. SANTOS, J. H. Do Empirismo à Fenomenologia - A Crítica do Psicologismo nas Investigaçôes Lógicas de Husserl, $\$ 11$, p. 110.

${ }^{34}$ Cf. Idem, $\$ 15$, p. 132. 
ataque psicologista”, a saber: como prescindir das conexôes causais - que são um fato psicológico e real - em troca de conexóes ideiais se estas só têm existência enquanto produzidas numa atividade psicológica e real? Talvez os lógicos tenham permitido tal contra-ataque justamente por entenderem que pensar tal relação entre o real e o ideal implicaria pensá-la como uma relação na qual o real seria a "fonte" da qual derivaria o ideal, como um empirista poderia pensar. Entretanto, que seja necessário reiterar a distinção entre tais domínios, não segue daí que a relaçáo entre os mesmos seja necessariamente uma relaçáo na qual o ideal fosse extraído do real (de modo que um derivasse do outro). A possibilidade e, até mesmo, a exigência de redimensionar o estatuto dessa relação, exigiria, por sua vez, que se reservasse à experiência um lugar específico, sem que, todavia, tal lugar reservado significasse a aceitaçáo de um empirismo. Conforme se mostrou, em linguagem kantiana, Husserl assumiria, ao responder à referida exigência, uma posição específica quanto à experiência, tomando-a não como "fonte de conhecimento", mas como começo imprescindível para se pensar a referida relação entre os processos psicológicos e o conteúdo lógico do pensamento, sem que, com isso, incorresse em um empirismo nos moldes psicologistas. Como recorda Júlio Fragata, em A Fenomenologia como Fundamento da Filosofia (1959), “[...] as leis lógicas não são inferências da experiência psicológica, embora só por meio dela se possam conhecer" 35 .

O reflexo dessa "dupla exigência" (diferenciar e relacionar o real e o ideal) poderá, por sua vez, ser notado em 1913, em Ideias I, a propósito da temática da constituição dos objetos intencionais. Ao tomar a intencionalidade como “objetividade imanente", situando-a em uma regiáo transcendental, Husserl afirma-nos, conforme vimos, que, na trama da constituição intencional, os dados sensíveis assumem um papel decisivo, na medida em que, no fluxo do vivido em geral, os mesmos servem de "suporte" para os atos intencionais que, por sua vez, animam o vivido de significaçôes. Novamente, em linguagem kantiana, reaparece a concepção segundo a qual a doação de sentido dos atos noéticos da consciência intencional não deriva dos dados sensíveis (materiais ou hiléticos), porém, não começa sem eles. Aqui, apresentando-nos uma concepção "hilético-morfista" do vivido, Husserl expressa, uma vez mais, a lição kantiana, já anunciada ao final do Capítulo Quarto de "Prolegômenos": o conhecimento não deriva da experiência, mas deve começar com ela. Tratarse-ia, certamente, como nos lembra Joáo Paisana, em Husserl e a ideia de Europa (1997), da influência exercida pelo neokantismo da Escola de Marburg

${ }^{35}$ Cf. FRAGATA, J. A Fenomenologia como Fundamento da Filosofia, p. 40. 
- principalmente, através de Natorp - sobre o pensamento de Husserl, nas origens da fenomenologia ${ }^{36}$. Os influxos exercidos pelo neokantismo sobre o projeto da fenomenologia transcendental de Husserl seriam, certamente, de suma importância no encaminhamento do lugar reservado à experiência no projeto da filosofia fenomenológica até $1913^{37}$.

Contudo, no que concerne à concepçáo hilético-morfista do vivido, como o próprio Husserl insiste em ressaltar, no $\$ 85$ de Ideias $I$, tais dados sensíveis assumem um papel decisivo na trama que envolve a constituição dos objetos intencionais, pois as intençôes somente animam o vivido de significações na medida em que atuam sobre esse "substrato" sensível que, como tal, nada designa, uma vez que é "não-intencional". Apesar de tal importância atribuída aos dados materiais na constituição intencional dos objetos, o próprio Husserl é explícito ao sustentar que ahilética - enquanto uma modalidade de análise fenomenológica - seria incomparavelmente menos importante e, portanto, menos rica que a noética fenomenológica. Em Husserl, tal afirmação será determinante do modo como deveremos entender o lema fenomenológico do "retorno às coisas mesmas" ( $Z u$ den Sachen selbst). Em História da Filosofia no século XX (1997), Christian Delacampagne chega mesmo a sugerir que, movido por esse lema, Husserl parece ter produzido pouco a pouco um desvio do mundo real, manifestando, com isso, "[...] uma certa impotência de pensar o real na complexidade das suas determinaçōes" ${ }^{38}$. Após ressaltar o papel decisivo assumido pelos dados hiléticos (sensíveis ou materiais) na trama que envolve a constituição dos objetos intencionais, Husserl não hesita em estabelecer, no projeto da fenomenologia transcendental, uma hierarquia na qual a hilética se encontraria abaixo da noética fenomenológica, em termos de importância. De uma maneira ou de outra, tal posição husserliana parece ter sido determinante na orientação tomada, na primeira metade do século XX,

${ }^{36}$ Cf. PAISANA, J. Husserl e a Ideia de Europa. Porto: Contraponto, 1997, p. 16-17.

${ }^{37}$ No que se refere às influências que a leitura de Kant exerceu sobre o pensamento husserliano, sobretudo, a partir de 1907, Walter Biemel - editor alemấo das "Cinco Liçôes" (Die Idee der Phänomenologie - Fünf Vorlesungen) - lembra-nos: "Husserl, nesta época, ocupou-se detidamente de Kant; desta ocupação veio-lhe a ideia da fenomenologia como filosofia transcendental, como idealismo transcendental...”. O manuscrito (Setembro de 1907, B II 1) é citado por Walter Biemel no texto de apresentação à edição alemã das "Cinco Liçôes". Lovaine, Setembro de 1947, p. IX. Em outra ocasião, tivemos a oportunidade de tratar de alguns tópicos referentes à relaçáo entre o idealismo transcendental de Kant e a fenomenologia de Husserl (Cf. TOURINHO, C. D. C. A ampliação da auto-reflexão da consciência: Kant e sua influência sobre a fenomenologia transcendental de Edmund Husserl. In: Princípios - Revista de Filosofia (UFRN). Volume 18, número 30, p. 199-210, jul-dez de 2011.

${ }^{38}$ Cf. DELACAMPAGNE, C. História da Filosofia no Século XX. Rio de Janeiro: Jorge Zahar, 1997, p. 36-37. 
pelos adeptos da fenomenologia que, inconformados com tal desvio em relação ao mundo real, foram, cada um a seu modo, se afastando de Husserl. Porém, uma análise mais detalhada das dissidências produzidas pelo movimento fenomenológico-existencial em relação à fenomenologia de Husserl ficará para uma outra ocasião.

TOURINHO, Carlos D. C. The place of experience in Husserl's phenomenology: from the Prolegomena to Ideas I. Trans/Form/Ação, Marília, v. 36, n. 3, p. 35-52. Set./Dez., 2013.

\begin{abstract}
This article discusses the place of experience in the origins of phenomenology in Husserl's Prolegomena to Pure Logic (1900). It is shown that Husserl assumes a specific position regarding the role of experience in the debate on the relationship between logic and psychology. The article also discusses the effects of the Husserlian position in Ideas I (1913) concerning the issue of the constitution of intentional objects. Husserl indicates the critical role assumed by sense data, which serve as "support" for intentionality. It is pointed out that the giving of meaning that occurs through intentional acts of consciousness does not derive from sense data; however, it also does not start without such data.
\end{abstract}

KEYWORDS: Phenomenology. Husserl. Experience. Sense data. Intentional living.

\title{
REFERÊNCIAS
}

BRENTANO, F. Psychologie vom empirischen Standpunkt. Erster Band. Hamburg: Felix Meiner, ([1874] 1973).

DELACAMPAGNE, C. História da Filosofia no Século XX. Rio de Janeiro: Jorge Zahar, 1997.

FRAGATA Sj, J. A Fenomenologia de Husserl como fundamento da filosofia. Braga: Cruz, 1956.

HUSSERL, E. Logische Untersuchungen. Erster Band. Prolegomena zur reinen Logik. Halle a. d. S.: Max Niemeyer, ([1900] 1913).

. Logische Untersuchungen. Zweiter Band. Erster Teil. Untersuchungen zur Phänomenologie und Theorie der Erkenntnis. Halle a. d. S.: Max Niemeyer, ([1901] 1913).

Die Idee der Phänomenologie - Fünf Vorlesungen. Husserliana (Band II). Netherlands: Martinuos Nijhoff, ([1907] 1950). 
Ideen zu einer reinen Phänomenologie und phänomenologischen Philosophie. Erstes Buch: Allgemeine Einführung in die reine Phänomenologie. Halle a. d. S.: Max Niemeyer, 1913.

. Cartesianische Meditationen und Pariser Vorträge. Husserliana (Band I). Den Haag, Netherlands: Martinuos Nijhoff, ([1931] 1973).

KANT, I. Kritik der reinen Vernunft. Leipzig: Felix Meiner, ([1787] 1919).

PAISANA, J. Husserl e a Ideia de Europa. Porto: Contraponto, 1997.

SANTOS, J. H. Do empirismo à fenomenologia. A crítica do psicologismo nas Investigaçóes Lógicas de Husserl. Sáo Paulo: Loyola, 2010.

TOURINHO, C. D. C. A ampliação da auto-reflexão da consciência: Kant e sua influência sobre a fenomenologia transcendental de Edmund Husserl. Princípios - Revista de Filosofia (UFRN). Volume 18, número 30, p. 199-210, jul-dez de 2011.

Recebido em: 18.03.2013

Aceito em: 25.07.2013 
TOURINHO, C. D. C. 